\title{
Trends in surgical treatment of Chiari malformation Type I in the United States
}

\author{
D. Andrew Wilkinson, MD, Kyle Johnson, BS, Hugh J. L. Garton, MD, MSc, \\ Karin M. Muraszko, MD, and Cormac O. Maher, MD \\ Department of Neurosurgery, University of Michigan, Ann Arbor, Michigan
}

OBJECTIVE The goal of this analysis was to define temporal and geographic trends in the surgical treatment of Chiari malformation Type I (CM-I) in a large, privately insured health care network.

METHODS The authors examined de-identified insurance claims data from a large, privately insured health care network of over 58 million beneficiaries throughout the United States for the period between 2001 and 2014 for all patients undergoing surgical treatment of CM-I. Using a combination of International Classification of Diseases (ICD) diagnosis codes and Current Procedural Terminology (CPT) codes, the authors identified CM-I and associated diagnoses and procedures over a 14-year period, highlighting temporal and geographic trends in the performance of CM-I decompression (CMD) surgery as well as commonly associated procedures.

RESULTS There were 2434 surgical procedures performed for CMD among the beneficiaries during the 14-year interval; $34 \%$ were performed in patients younger than 20 years of age. The rate of CMD increased $51 \%$ from the first half to the second half of the study period among younger patients $(p<0.001)$ and increased $28 \%$ among adult patients between 20 and 65 years of age ( $p<0.001$ ). A large sex difference was noted among adult patients; $78 \%$ of adult patients undergoing CMD were female compared with only $53 \%$ of the children. Pediatric patients undergoing CMD were more likely to be white with a higher household net worth. Regional variability was identified among rates of CMD as well. The average annual rate of surgery ranged from 0.8 surgeries per 100,000 insured person-years in the Pacific census division to 2.0 surgeries per 100,000 insured person-years in the East South Central census division.

CONCLUSIONS Analysis of a large nationwide health care network showed recently increasing rates of CMD in children and adults over the past 14 years.

https://thejns.org/doi/abs/10.3171/2016.8.PEDS16273

KEY WORDS Chiari malformation Type I; prevalence; surgical treatment

O HIARI malformation Type I (CM-I) is a common reason for neurosurgical referral in both children and adults. Though this condition was originally thought to be rare, estimates of its prevalence among patients undergoing MRI in the modern era range from $0.8 \%$ to $3.7 \%$ in children ${ }^{1,27,41}$ and from $0.24 \%$ to $0.9 \%$ in adults. ${ }^{30,44}$ In contrast to its imaging prevalence, symptomatic CM-I is relatively rare. ${ }^{1}$

Most studies of surgically treated patients have been single-center series. $1,2,4,5,8,9,11,21,24,26,32,35,42,43,46$ The rate of CM-I decompression (CMD) surgery in the United States is not well defined. Several recent studies have used inpatient administrative data and, with a validated algorithm and facility billing data to identify Chiari operations, have noted complications and resource use among surgically treated adult and pediatric patients in 3 states. ${ }^{14-16,22}$ Another study accessed the Kids' Inpatient Database (KID) to analyze posterior fossa decompressions nationwide using a combination of International Classification of Diseases, 9th edition (ICD-9) diagnosis and procedure codes. ${ }^{38}$ These authors primarily examined outcomes and complications of duraplasty versus no duraplasty but did not find a temporal change in the rate of surgery among children. Furthermore, other procedures such as shunt placement, occipitocervical fusion,,$^{3,7}$ or cord untethering ${ }^{12,28,36}$ are sometimes performed in proximity to the CMD surgery at

ABBREVIATIONS CM-I = Chiari malformation Type I; CMD = CM-I decompression; CPT = Current Procedural Terminology; ICD-9-CM = International Classification of Diseases, 9th edition, Clinical Modification.

SUBMITTED May 17, 2016. ACCEPTED August 16, 2016.

INCLUDE WHEN CITING Published online November 11, 2016; DOI: 10.3171/2016.8.PEDS16273. 


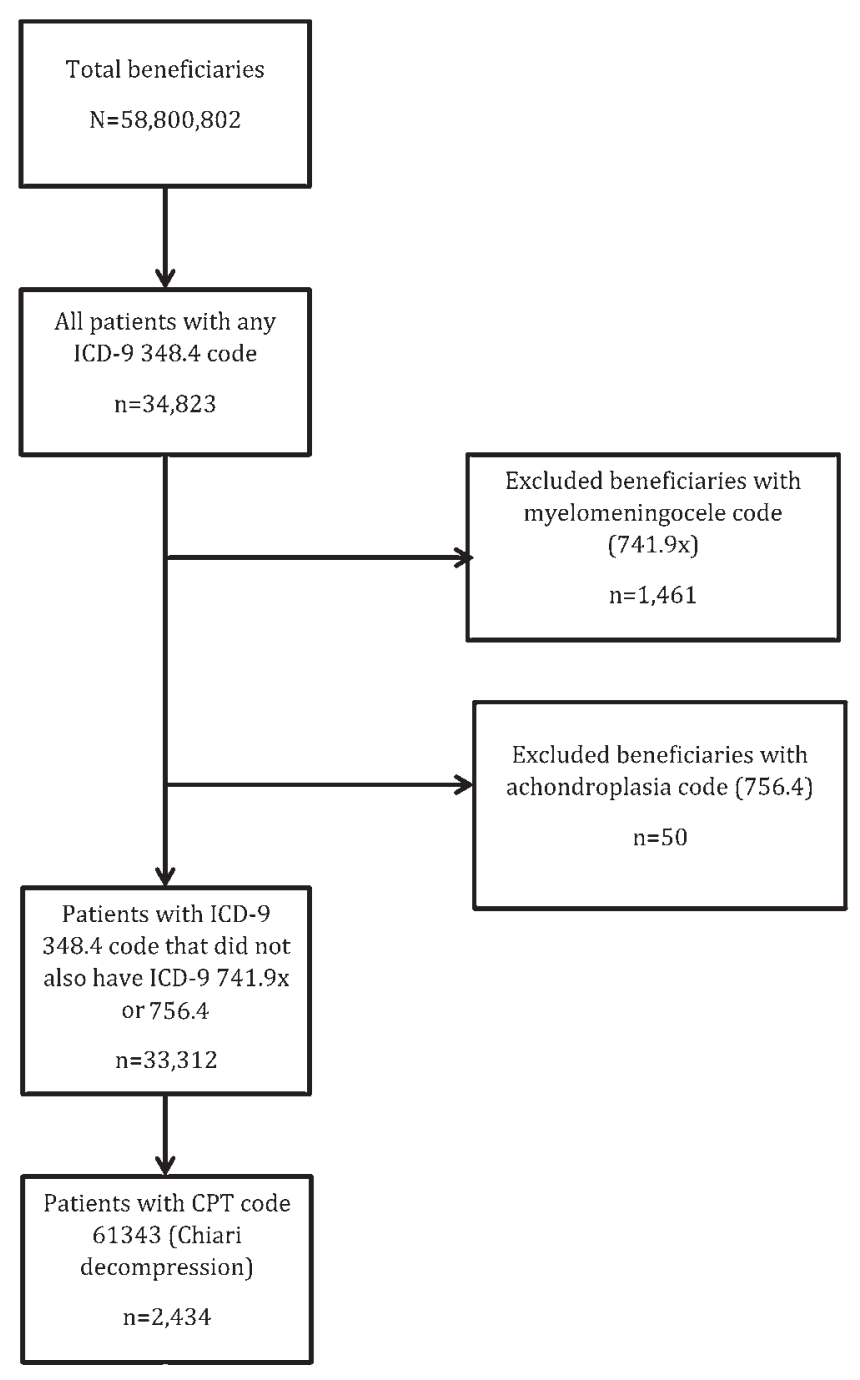

FIG. 1. Search method combining CPT codes with ICD-9 codes to identify patients undergoing $\mathrm{CMD}$ in the Optumlnsight data set.

some centers. The frequency with which these procedures are performed nationwide has not been described. To date, no study has examined the national prevalence, regional variability, or temporal trends in the performance of $\mathrm{CM}$ surgery and associated procedures.

\section{Methods}

The Clinformatics Data Mart database (OptumInsight) contains health care claims data for all beneficiaries in a managed-care network with enrollees throughout the US. This data set comprises all enrollees who had participating medical and pharmacy insurance coverage at any time between January 1, 2001, and December 31, 2014-a total of 58,800,802 unique patients. Medicare-eligible individuals are included only if they have supplemental coverage through a private insurer. Data are organized by a specific patient identification number that patients retain, ensuring longitudinal follow-up that persists despite changes in plan details or gaps in insurance coverage. The data set includes information on medical claims for all conditions for these enrollees-demographic information such as age,
TABLE 1. United States census divisions

\begin{tabular}{ll}
\hline \multicolumn{1}{c}{ Census Division } & \multicolumn{1}{c}{ States } \\
\hline East North Central & Indiana, Illinois, Michigan, Ohio, Wisconsin \\
\hline East South Central & Alabama, Kentucky, Mississippi, Tennessee \\
\hline Middle Atlantic & New Jersey, New York, Pennsylvania \\
\hline Mountain & $\begin{array}{c}\text { Arizona, Colorado, Idaho, New Mexico, Mon- } \\
\text { tana, Utah, Nevada, Wyoming }\end{array}$ \\
\hline New England & $\begin{array}{c}\text { Conneticut, Maine, Massachusetts, New Hamp- } \\
\text { shire, Rhode Island, Vermont }\end{array}$ \\
\hline Pacific & Alaska, California, Hawaii, Oregon, Washington \\
\hline South Atlantic & $\begin{array}{c}\text { Delaware, District of Columbia, Florida, } \\
\text { Georgia, Maryland, North Carolina, South } \\
\text { Carolina, Virginia, West Virginia }\end{array}$ \\
\hline West North Central & $\begin{array}{c}\text { lowa, Kansas, Minnesota, Missouri, Nebraska, } \\
\text { North Dakota, South Dakota }\end{array}$ \\
\hline West South Central & Arkansas, Louisiana, Oklahoma, Texas \\
\hline
\end{tabular}

sex, race, education level, and income as well as outpatient pharmacy prescriptions that were filled. This data set has been used in other fields, including cardiology, neurology, and ophthalmology. . $^{33,34,45}$

Because the data were de-identified before we obtained them, the University of Michigan Institutional Review Board considered this a nonregulated study. We searched all claims for those with an ICD-9-Clinical Modification (ICD-9-CM) code of 348.4 (compression of brain, including CM-I). For patients who had a 348.4 ICD-9 diagnosis code listed for any medical claim, we examined all other claims, including inpatient and outpatient encounters as well as pharmacy prescriptions. Those with a diagnosis code of myelomeningocele without hydrocephalus (741.9x) or achondroplasia (756.4) were excluded from analysis to eliminate CM-II operations or foramen magnum decompressions. The claims were then searched for those containing a Current Procedural Terminology (CPT) code of 61343 (CMD) for the period from January 1,2001 , through December 31,2014 . In the case of multiple CPT 61343 claims, only the first was counted to represent the index surgery (Fig. 1).

For claims that had CMD surgery for CM-I, we searched for other CPT codes to identify other surgical procedures performed at any point either before or after the CM surgery, including ventricular shunt placement (CPT 62220, 62223), cervical fusion (CPT 22590, 22595, 22548), and spinal cord untethering (CPT 63200). The ICD-9 diagnosis codes from any claim were used to identify the comorbidities of syringomyelia (336.0), hydrocephalus (742.3, 331.x), and scoliosis (737.3x, 754.2). Results were stratified by age group, sex, year of operation, and US census division (Table 1). The average longest duration of consecutive insurance coverage was calculated for all beneficiaries of the plan, as well as for those undergoing CMD. Gaps in coverage of less than 1 month were considered as continuous coverage since eligibility was usually retroactive.

For this analysis, we considered a patient to have undergone a CMD if they had 1) an ICD-9 Chiari diagnosis code in any claim and 2) no myelomeningocele or achondroplasia ICD-9 diagnosis code in any claim and 3) a 
TABLE 2. Comparison of pediatric and adult patients undergoing CMD

\begin{tabular}{|c|c|c|c|c|}
\hline \multirow[b]{2}{*}{ Variable } & \multicolumn{3}{|c|}{ No. (\%) } & \multirow[b]{2}{*}{$p$ Value } \\
\hline & Total & $\begin{array}{l}\text { Pediatric } \\
\text { Group }\end{array}$ & $\begin{array}{l}\text { Adult } \\
\text { Group }\end{array}$ & \\
\hline Total CMD surgeries & 2434 & $841(34.6)$ & $1593(65.4)$ & \\
\hline Male & $748(30.7)$ & $397(47.2)$ & $351(22.0)$ & $<0.0001$ \\
\hline Female & $1686(69.3)$ & $444(52.8)$ & $1242(78.0)$ & \\
\hline \multicolumn{5}{|l|}{$\begin{array}{l}\text { Neurological comor- } \\
\text { bidities }\end{array}$} \\
\hline Hydrocephalus & $306(12.6)$ & $116(13.8)$ & $190(11.9)$ & 0.19 \\
\hline Scoliosis & $315(12.9)$ & $207(24.6)$ & $108(6.8)$ & $<0.0001$ \\
\hline Syrinx & $792(32.5)$ & $351(41.7)$ & $441(27.7)$ & $<0.0001$ \\
\hline \multicolumn{5}{|l|}{$\begin{array}{l}\text { Associated proce- } \\
\text { dures }\end{array}$} \\
\hline $\begin{array}{c}\text { Shunt place- } \\
\text { ment }\end{array}$ & $100(4.1)$ & $30(3.6)$ & $70(4.4)$ & 0.33 \\
\hline $\begin{array}{l}\text { Occipitocervical } \\
\text { fusion }\end{array}$ & $63(2.6)$ & $19(2.3)$ & $44(2.8)$ & 0.45 \\
\hline Untethering & $23(0.9)$ & $14(1.7)$ & $9(0.6)$ & 0.008 \\
\hline
\end{tabular}

claim containing the CPT code 61343 for a given date. Repeat CMDs were not considered for analysis. Facility billing data corresponding to discrete hospitalizations for plan beneficiaries were also available for the portion of the study period from 2004 to 2014. For each admission, discharge ICD diagnosis and procedure codes were evaluated.

Standard descriptive statistics via chi-square analysis for categorical bivariate analysis and 2-sided Student ttest for continuous variables were used to describe demographic characteristics and compare rates of surgery after dichotomizing the study period into early (2001-2007) and late (2008-2014) surgeries. Statistical analyses were performed using SAS software version 9.4 (SAS Institute) and Microsoft Excel 2011 (Microsoft Corp.). To compare our results from analysis via ICD and CPT codes, we used a previously validated algorithm to identify CMDs from facility billing data - that is, a primary ICD-9 diagnosis code of 348.4 as well as an ICD procedure code of either 01.24 (cranial decompression) or 03.09 (spinal decompression)..$^{15,22}$

\section{Results}

Our search identified 2434 index CMD procedures from 2001 to 2014, and the demographic characteristics of these cases are described in Table 2. Among these cases were 841 patients $(34.6 \%)$ who were 20 years of age or younger (children) at the time of surgery. The number of patients also diagnosed with hydrocephalus was similar between the age groups $(13.8 \%$ in children vs $11.9 \%$ in adults, $\mathrm{p}=0.19$ ). Coding for scoliosis was more prevalent in children $(24.6 \%$ vs $6.8 \%, \mathrm{p}<0.0001)$, as was coding for spinal cord syrinx $(41.7 \%$ in children vs $27.7 \%$ in adults, $\mathrm{p}$ $<0.0001)$. Rates of shunt placement either before or after surgery were similar between age groups $(3.6 \%$ in children vs $4.4 \%$ in adults, $p=0.33$ ). The rate of cervical fu-

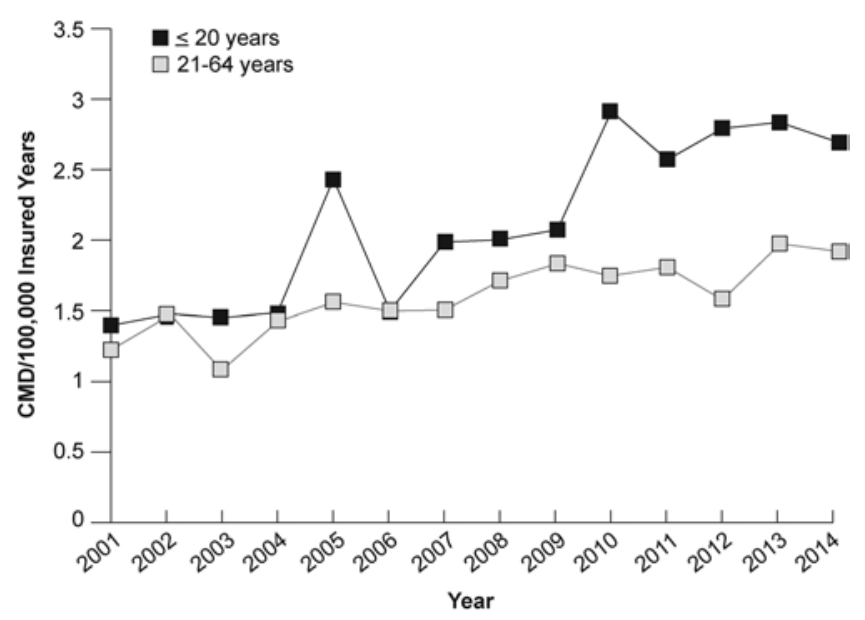

FIG. 2. Annual rate of CMD over a 14 -year interval. Pediatric patients (age $\leq 20$ years) had an increasing rate of CMD over the interval. Adult patients younger than 65 years also had a smaller, but still significant, increased rate of CMD.

sion was also similar (2.3\% in children vs $2.8 \%$ in adults, $\mathrm{p}=0.45$ ). Children were more likely to undergo a spinal untethering procedure $(1.7 \%$ in children vs $0.6 \%$ in adults, $\mathrm{p}=0.008)$.

The average number of insured member-months per year over the 14-year period was 136,957,682 (range from $110,179,001$ in 2001 to $150,381,400$ in 2013). The proportion of insured members in each age group was stable over the study period except for members over 65 years of age, who had an increase in enrollment in private insurance because of the implementation of the Medicare prescription drug benefit (Medicare Part D) in 2006. Consequently, CMD rates in adults were calculated among the non-Medicare-eligible population. The average continuous insurance enrollment period for patients undergoing CMD was 1686 days, while the average continuous enrollment period for all patients in the database was 918 days. The annual insured member-months per year for pediatric patients ranged from $30,762,872$ to $36,396,528$. The incidence of CM diagnosis without surgery could not be reliably calculated given the lack of specificity of the diagnostic code alone (ICD-9 348.4) without the corresponding surgery code (CPT 61343). However, we noted that the number of patients having a first-time-use of the code 348.4 nearly tripled from 10 per 100,000 insured patient-years in 2001 to 27 per 100,000 insured patientyears in 2014.

The number of CMD procedures per enrolled beneficiary per year was calculated for each year (Fig. 2), stratified according to pediatric and nonelderly adult age groups. The average yearly rate of CMD surgery for nonelderly adults increased $28 \%$ over the study period, averaging 1.4 per 100,000 adult enrolled years from 2001 to 2007 and 1.8 per 100,000 from 2008 to 2014 ( $p<0.001$ ). Among pediatric patients, the average yearly rate increased $51 \%$, from 1.7 per 100,000 enrolled years from 2001 to 2007 to 2.5 per 100,000 from 2008 to 2014 ( $p<0.001)$. The rate of cervical fusion and cord untethering showed an increasing trend with time but did not reach significance when rates between 2001-2007 and 2008-2014 were compared us- 


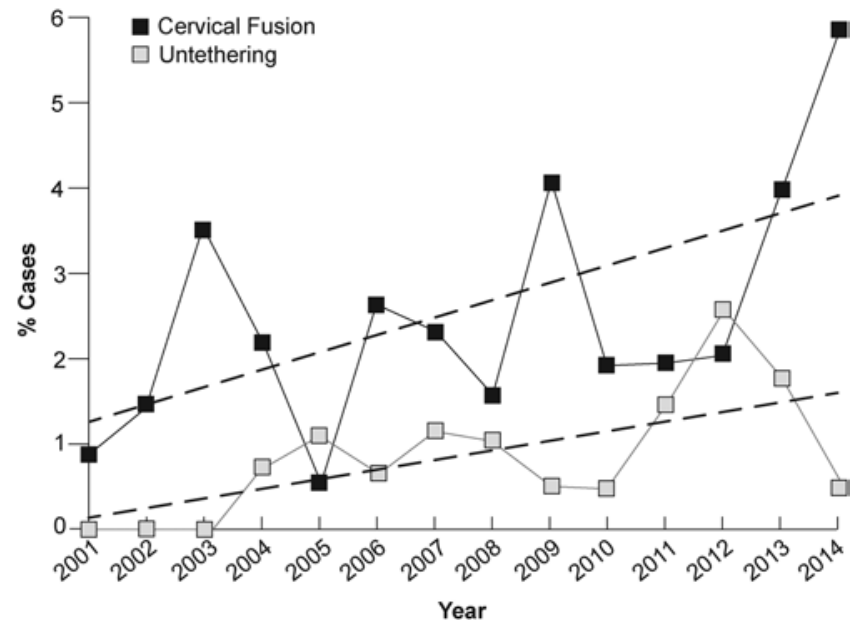

FIG. 3. Incidence of other surgical procedures in patients who underwent CMD. Trend lines added for cervical fusion $\left(R^{2}=0.32\right)$ and untethering $\left(R^{2}=0.40\right)$. Dichotomized comparison of $2001-2007$ versus 2008-2014 approached but did not reach significance for cervical fusion $(p=0.07)$ and untethering $(p=0.13)$.

ing chi-square analysis $(p=0.07$ for cervical fusion, $p=$ 0.13 for untethering). Notably, the last 2 years of the study showed the highest rates of concurrent cervical fusion, with $4.0 \%$ and $5.9 \%$ of CMD cases also undergoing cervical fusion (Fig. 3). The rate of shunt placement did not change over the study period.

The age distribution of patients undergoing CMD showed a bimodal peak, with the largest number of patients undergoing surgery in the 15- to 19-year-old age group and a later peak from ages 35 to 39 years (Fig. 4). The sex distribution of those undergoing CMD varied significantly according to age (Figs. 5 and 6). Most of the patients undergoing CMD in early childhood were males, but females comprised a majority of all CMD patients beginning in the 2 nd decade. Female patients showed large variations in the number of CMDs performed in each age range, and the bimodal peak seen among the total population was largely attributable to the female population. In contrast, male patients had rates of CMD that were stable

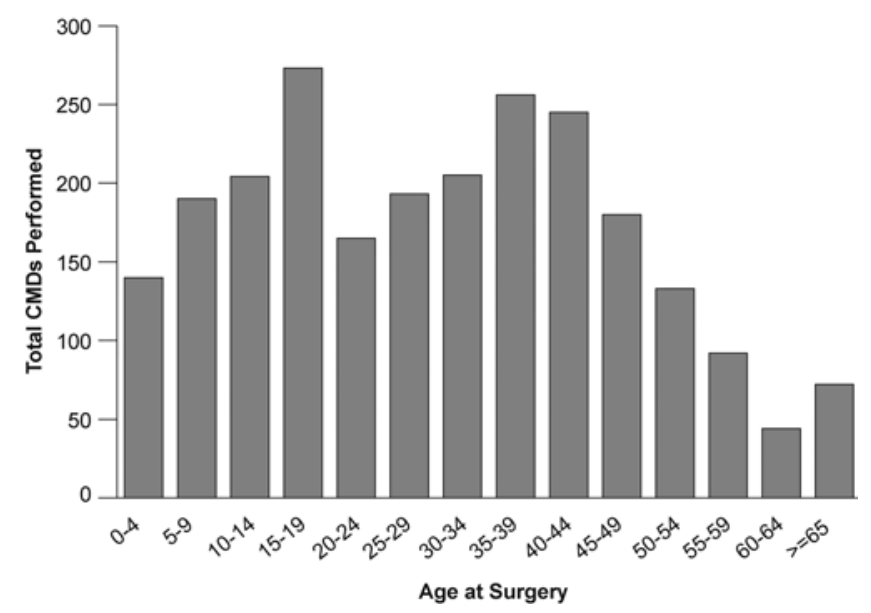

FIG. 4. Total number of CMDs by age.

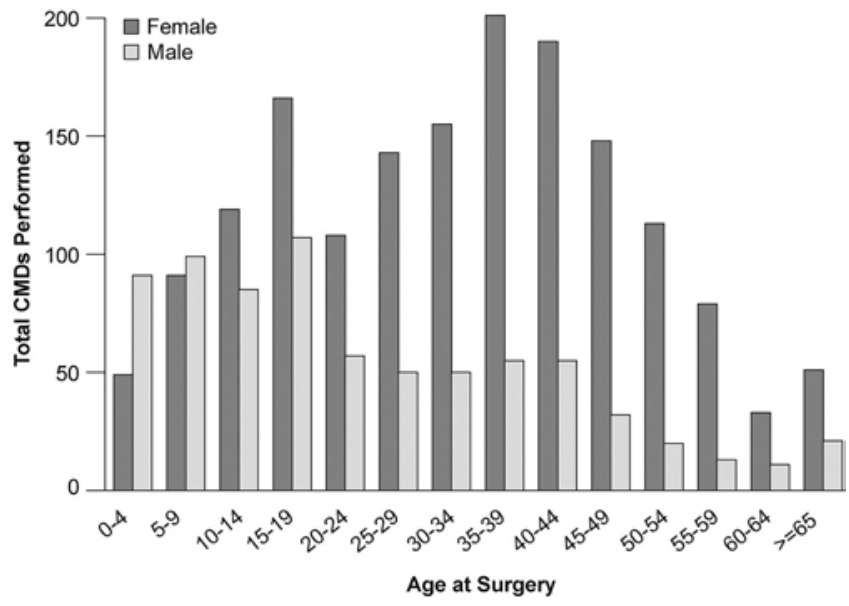

FIG. 5. Total number of CMDs by age and sex.

through childhood, dropped slightly, and then remained largely stable through adulthood. Among pediatric patients, 444 (52.8\%) were female; among adult patients, however, $1242(78.0 \%)$ were female $(\mathrm{p}<0.0001)$. Within the pediatric group, CMD was performed more frequently in boys in the 0 - to 14 -year-old age group, equally in girls and boys in the 5- to 9-year-old age group, and more frequently in girls in later childhood, reflecting a trend toward the adult sex distribution.

Race, household income, and household net worth were reported for $85.7 \%$ of enrollees in the health insurance coverage network, although some fields were missing or unknown for each category. Data stratified by age (pediatric vs adult) are reported for all enrollees in the data set as well as those undergoing CMD (Table 3). Significant differences were found in race, household income, and household net worth when comparing all enrollees and those undergoing CMD, in both the pediatric and adult populations. Among the pediatric population, those undergoing CMD were more likely to be white $(85.9 \%$ vs $72.6 \%$, p < 0.001 ) and from households with a net worth greater than $\$ 250,000$ (42.7\% vs $33.4 \%, \mathrm{p}<0.001)$. Among the adult population, racial differences were present but less pronounced, whereas household income and net worth were

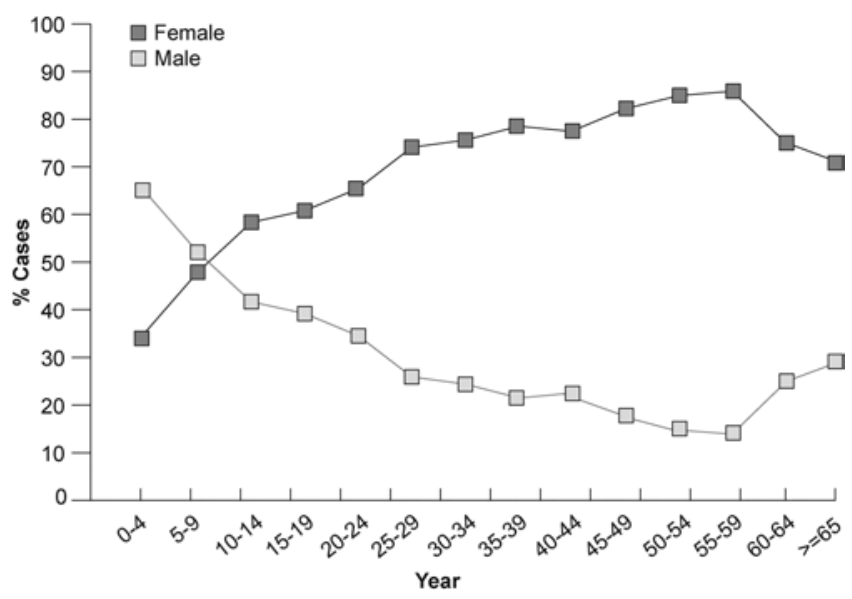

FIG. 6. Sex distribution of patients undergoing CMD by age. 
TABLE 3. Race, household income, and household net worth of pediatric and adult patients undergoing CMD

\begin{tabular}{|c|c|c|c|c|c|c|}
\hline \multirow[b]{2}{*}{ Variable } & \multicolumn{3}{|c|}{ Pediatric Group } & \multicolumn{3}{|c|}{ Adult Group } \\
\hline & All Enrollees & CMD Surgery & $p$ Value & All Enrollees & CMD Surgery & $p$ Value \\
\hline \multicolumn{7}{|l|}{ Race } \\
\hline White & $72.6 \%$ & $85.9 \%$ & $<0.001$ & $73.8 \%$ & $76.0 \%$ & 0.05 \\
\hline Non-white & $27.4 \%$ & $14.1 \%$ & & $26.2 \%$ & $24.0 \%$ & \\
\hline \multicolumn{7}{|c|}{ Household income range } \\
\hline$\$ 100 K+$ & $49.2 \%$ & $52.9 \%$ & 0.09 & $36.0 \%$ & $31.7 \%$ & 0.005 \\
\hline$<\$ 100 \mathrm{~K}$ & $50.8 \%$ & $47.1 \%$ & & $64.0 \%$ & $68.3 \%$ & \\
\hline \multicolumn{7}{|c|}{ Household net worth } \\
\hline$\$ 250 \mathrm{~K}+$ & $33.4 \%$ & $42.7 \%$ & $<0.001$ & $40.3 \%$ & $31.5 \%$ & $<0.001$ \\
\hline$<\$ 250 \mathrm{~K}$ & $66.6 \%$ & $57.3 \%$ & & $59.7 \%$ & $68.5 \%$ & \\
\hline
\end{tabular}

both lower in patients undergoing CMD as compared with the larger insured population.

Chiari malformation decompression surgeries were also stratified by region according to the US census division. Census division data were available for all but 5 of the 2434 patients who underwent a CMD procedure. The number of insured person-years per census division over the analyzed time period was calculated using the longest continuous coverage period for each enrollee. The annual rate of surgery for each census division was then calculated per 100,000 insured person-years (Fig. 7). The average annual rate of surgery ranged from 0.8 surgeries per 100,000 insured person-years in the Pacific census division to 2.0 surgeries per 100,000 insured person-years in the East South Central census division. One-way ANOVA revealed a statistically significant difference between group means ( $\mathrm{p}<0.001)$, and the resulting extremal quotient was 2.5.

When we compared our own data obtained using our search methods to data that we derived by applying the techniques of Ladner et al. ${ }^{15,22}$ to our own data set, we found good correlation between the 2 techniques. Figure 8 shows the results of verifying our algorithm for identifying CMDs via ICD diagnosis and CPT procedure codes as

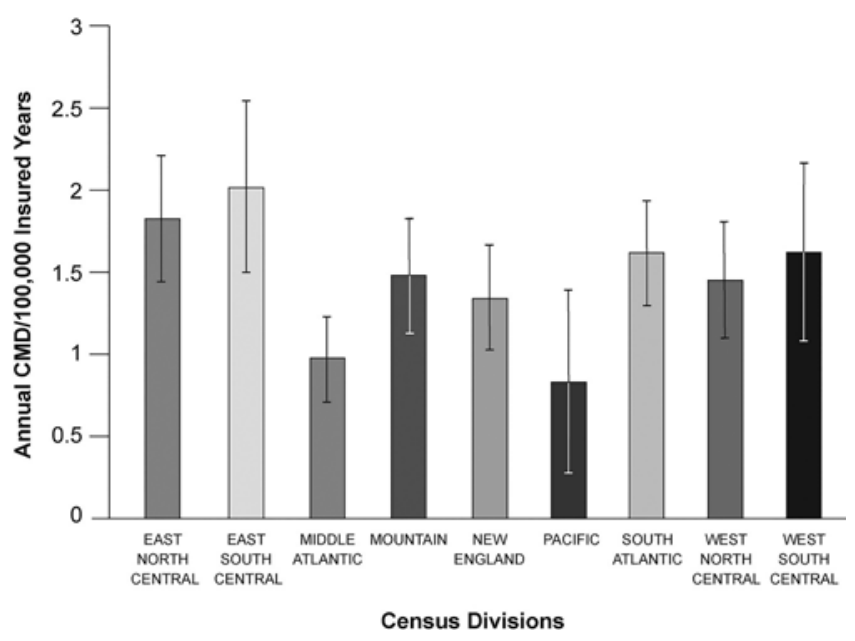

FIG. 7. Regional variation in the rate of CMD. Average annual rate with the standard deviation shown. compared with a validated algorithm using confinement data available from 2004 to 2014 for our population.

\section{Discussion}

We used a combination of ICD-9 diagnosis codes and CPT procedure codes to identify, from among a group of 58.8 million beneficiaries in a private managed-care network of enrollees throughout the US, 2434 patients who had undergone CMD procedures over a 14-year period. The results of our identification of CMD procedures correlated well with those obtained using a validated algorithm for the portion of the study time period for which hospital admission data were available..$^{15,22}$ Previous studies of CMD have been primarily single-institution series on patients surgically treated at large academic institutions. Two groups of investigators, both using a sampling of hospital discharge data, have recently examined the performance of CMD on a multistate or national level. Analyses based on hospital discharge data alone do not allow one to estimate the incidence of surgery within a larger population since the denominator of patients served can only be estimated. ${ }^{14,16,38}$ The nature of our data set, in which a finite number of patients were fully insured, allowed for these

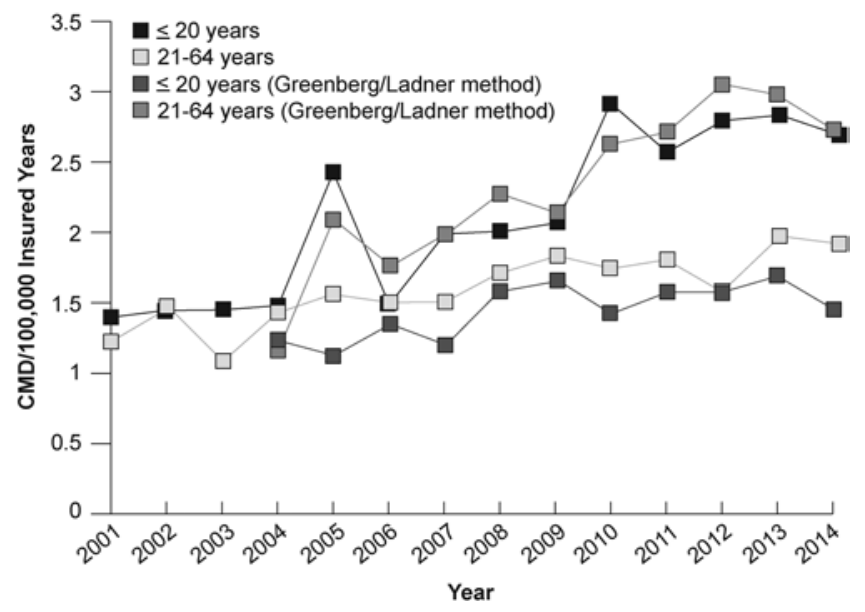

FIG. 8. Comparison of our method of CMD identification in the Clinformatics Data Mart database versus the methods of Greenberg et al. and Ladner et al., showing good concordance and year-to-year variation. 
analyses, as well as an estimation of regional variability and temporal trends in the performance of CMD and accompanying surgeries among the insured population.

\section{Temporal Trends}

The increasing incidence of surgery in both the pediatric and adult populations noted in our study has been suggested by a multicenter validation study in which the number of surgeries increased significantly in 2009-2013 compared with the number in 2001-2008 at 3 academic medical centers, though it was unclear if this finding simply represented an increasing performance of CMD at tertiary care centers. ${ }^{15,22}$ One previous study of a national pediatric inpatient database did not show a change in treatment rates from 2001 to $2009 .{ }^{38}$ However, we note that that study covered a time interval prior to the period for which we found an increasing performance of CMD and that the investigators used an unvalidated algorithm for identifying CM-I cases that did not exclude CM-II and did not account for alternate methods of ICD coding for CMD. While our analysis does not allow for a complete explanation for the increasing rate of CMD, we speculate that given the welldocumented rise in diagnostic imaging over the past 15 years, ${ }^{40}$ increased radiological identification of CM may lead to more CM diagnoses and a subsequent increase in $\mathrm{CM}$ patients undergoing surgery. While the individual ICD-9 diagnostic code 348.4 is nonspecific and alone is insufficient to identify the diagnosis of CM-I, we do note that the annual number of patients assigned this diagnostic code for the first time nearly tripled from 2001 to 2014 .

\section{Sex and Age Distribution}

Among surgically treated patients we found that while more boys in the 0 - to 9-year-old age group underwent surgery, females outnumbered males in the teenage and adult age groups. Female patients showed increasing rates of surgery throughout childhood, peaked rates at ages 15-19 years, and a later peak at ages 35-39 years. Male patients had stable rates of CMD in childhood and lower but stable rates of CMD as adults. A high percentage (78\%) of adult CMD surgeries were performed in women. Previous series on CMD in adults have also noted that a majority of patients are female, ,29 whereas pediatric studies have reported nearly equal proportions of boys and girls. ${ }^{2,3,42}$ In a large series of patients undergoing MRI, the average tonsil position was lower in females than in males in all age groups, but the discrepancy increased with advancing age between childhood and middle age, with the smallest difference in tonsil position in the 0 - to 10 -year-old age group..$^{39}$ This finding may explain the increasing prevalence of females undergoing surgery as age advances from childhood to adulthood in our current analysis. Another pediatric series found that while rates of CM-I diagnosis on imaging were similar between girls and boys, girls were more likely to have an associated syrinx or scoliosis, ${ }^{41}$ possibly accounting for the increasing prevalence of diagnoses among girls in the teen years.

\section{Race and Socioeconomic Status}

As is typical of a commercial claims database, our pri- vately insured population is not representative of the population as a whole; it is wealthier and less racially diverse. Even within that population, however, CMD among the pediatric patients was more often performed in those who were white and from a higher-net-worth household compared with the total insured population. Results differed for adults undergoing CMD, however, given that both income and household net worth were lower than in the total insured population. The reason for this finding is unclear. Black or Hispanic race has been reported to be a predictor of medical complications after CMD in the pediatric population, but to our knowledge no study has examined race as a predictor of surgical treatment. ${ }^{16}$ We are not aware of any studies that have examined income or net worth.

\section{Syringomyelia}

Using claims from all sources, including practitioner and outpatient claims, we found an overall spinal cord syrinx diagnosis rate of $42 \%$ in children and $28 \%$ in adults who had undergone CMD. These rates were stable over the study period. Previous studies based on inpatient data that did not include outpatient claims revealed syringomyelia in $29 \%$ of children and $19 \%$ of adults undergoing CMD. ${ }^{14,16}$ Syrinx is probably under-coded in studies using administrative databases that are limited to inpatient data since the additional syrinx diagnosis is not essential for facility billing. A recent analysis of all children undergoing imaging at a single institution showed that $23 \%$ of children with CM-I also had syringomyelia ${ }^{41}$ The percentage of CM-I patients with a syrinx is higher in surgical series, and rates as high as $76 \%$ have been reported.6,42 A large compilation of 145 separate reports describing CMD indicated that $65 \%$ of CM-I patients undergoing CMD had an associated syrinx. ${ }^{2}$

\section{Tethered Cord}

The association between tethered spinal cord and CM-I is controversial. One group has diagnosed tethered spinal cord in up to $14 \%$ of patients with CM-I..$^{12,28,36}$ Another group has found no correlation between tethered cord and CM-I. ${ }^{25}$ After efforts to exclude CM-II patients with myelomeningocele, we found a small number of patients who had undergone a spinal cord untethering operation in addition to CMD. Although the overall numbers were small and the difference was not statistically significant, there was a trend toward an increasing frequency of untethering procedures, with 6 performed in the first half of the study period compared with 17 in the second half. We must emphasize that these data merely show that such operations were performed. We are unable to make any judgment about the utility of these untethering operations.

\section{Cervical Fusion}

Various rates of concurrent or associated cervical fusion operations in a subset of CM-I patients have been reported..$^{13,17,18}$ A large study of 500 surgically treated pediatric patients described cervical fusion in less than $1 \%, 42$ while at another center 19 of 101 surgically treated children had cervical fusion because of complex Chiari morphology. ${ }^{3}$ In the present study we found that $2.6 \%$ of pa- 
tients undergoing CMD also had cervical fusion. Although there appeared to be a trend toward the increased performance of fusion, with 19 procedures $(1.9 \%)$ performed in 2001-2007 compared with $44(3.1 \%)$ in 2008-2014, this trend only approached statistical significance $(p=0.07)$. It should be noted that the years with the highest rates of cervical fusion were the last 2 years in our analysis (2013 and 2014). Further study is required to see if this increase continues in subsequent years.

\section{Regional Variation}

Although the practices described in single-center surgical series differ significantly, we are aware of no largescale database descriptions of US regional variations in rates of CMD. One study of a national database described the number of surgeries performed in large regional categories (Northeast, West, Midwest, South) but did not estimate the total number of eligible patients in each region. ${ }^{38} \mathrm{We}$ calculated rates of surgery for each of the 9 US census divisions by dividing the number of surgeries performed by the total number of insured member-years in each region. Rates varied from 0.8 surgeries per 100,000 insured person-years in the Pacific region to 2.0 surgeries per 100,000 insured-years in the East South Central region (Fig. 7; $p<0.001$ for ANOVA difference between means).

\section{Study Limitations}

Administrative databases are increasingly used to analyze trends in and outcomes of treatment at a population level. The strengths as well as the limitations of these studies have been well-described. ${ }^{19,20,31,37}$ Clinical inference based on medical claims data are not as accurate as that based on a direct review of medical charts since the data in the former case were originally collected from the medical record for claims processing and payment as opposed to research. Even when codes are assigned as accurately as possible based on the clinical situation, there is a wide degree of variation in the sensitivity and specificity of ICD diagnosis codes, ICD procedure codes, and CPT codes. ${ }^{23}$ For this reason, much of our analysis was based on patients who had been assigned both ICD and CPT codes consistent with $\mathrm{CM}$ and decompression. The Clinformatics Data Mart database is also specifically limited in its applicability to the general population since it contains only privately insured patients or those with private supplemental insurance in addition to Medicare. Most administrative database research in neurosurgery has relied on inpatient facility admission data. The newer databases that include longitudinal follow-up; outpatient, provider, and prescription claims; and a denominator of the entire population of beneficiaries allow more opportunities to analyze the prevalence of disease and treatment outcomes. ${ }^{23}$ In the present study there were fewer instances of missing or unknown data for patients undergoing CMD than for other patients in the data set, presumably because of the increased number of claims and interactions with the health care system in the former group.

The more essential a code is to the billing process, the greater the likelihood it will be accurately included in the medical record and administrative data set. ${ }^{10,20}$ Conversely, events that are unimportant to the billing process are less likely to be correctly coded. The availability of CPT codes in our database allowed for direct identification of surgeries for which a neurosurgeon had submitted and an insurer had paid a bill for code 61343, "Craniectomy, suboccipital with cervical laminectomy for decompression of medulla and spinal cord, with or without dural graft (eg, ArnoldChiari malformation)." The ICD procedure codes, though important for facility fees, are not as specific for identifying procedures, and the performing surgeon is generally not involved in their application. Thus, given the specificity of this CPT code, its availability over the entire study period, and its future availability and planned use despite the implementation of ICD-10, we chose to use it for the identification of CMD. Since the CPT code 61343 is associated with a significant surgical fee, it is important for most or all surgeons to ensure that it is accurately included in the record. Use of the CPT code for CMD was the basis for the sensitivity determination of ICD codes performed by Greenberg et al. ${ }^{15}$ and Ladner et al. ${ }^{22}$ Similarly, the codes for associated surgical procedures are quite specific, and we believe that they are likely to be reliably recorded.

In some instances, ICD diagnosis codes continue to be useful, especially when combined with CPT codes for analysis. For example, we relied on ICD codes to exclude CM-II patients with myelomeningocele as well as patients with achondroplasia who had undergone foramen magnum decompression. Differentiating CM-I from CM-II by using administrative data can be challenging. Using record review to validate their algorithm for the identification of CMD, Greenberg et al. and Ladner et al. found that CM-II decompression was the most common cause of both falsepositives and false-negatives in their algorithm of choice for adults and the most common cause of false-negatives in children. ${ }^{15,22}$ We found that a large number of patients had diagnostic codes indicative of CM-I and CM-II in the medical record. Since all patients with CM-II have a diagnosis of myelomeningocele, we attempted to eliminate the patients with CM-II by excluding all patients who had a diagnosis of myelomeningocele anywhere in their medical record. Given that our database includes not only inpatient admissions but also outpatient visits, labs, and pharmacy claims - all of which require an associated diagnosis code when billing-we believe that our chances of missing a diagnosis of myelomeningocele would be reduced. Similarly, the most common false positive in identifying CM-I in children was foramen magnum decompression; ${ }^{22}$ therefore, we eliminated all patients with an ICD code for achondroplasia anywhere in the medical record.

To validate our methods, we applied the method of Greenberg and colleagues ${ }^{15,22}$ to our own data and found concordance with the data derived using our own methods. For our data set, facility discharge claims data were available only for the years 2004-2014. Using our method, we identified 718 pediatric CMD procedures and 1352 nonelderly adult CMD procedures in our data set over that time period. Using our data set and the method of Greenberg and colleagues, we found 725 pediatric CMD procedures and 1156 adult CMD procedures. We attribute the larger difference in the adult decompressions to the lower sensitivity found by Greenberg and colleagues in using their algorithm in adults (83\%) compared with its use in 
children (89\%). Year-to-year variation was similar using both methods, showing good concordance (Fig. 8).

\section{Conclusions}

We analyzed CMD over a 14-year interval by using a large nationwide administrative database including outpatient and inpatient information. The rate of CMD in children increased $51 \%$ from the first half of the study compared with the latter half, and the rate among nonelderly adults increased $28 \%$. A CMD was performed in more boys than girls under the age of 10 years. Among patients older than 10 years of age, females were more likely to undergo CMD, especially those in the adult age range. Pediatric patients undergoing CMD were more likely to be white and to come from a household with a higher net worth. A nonsignificant trend in the increasing frequency of cervical fusion and spinal cord untethering was seen over the study period. Significant regional variability was identified, with double the rates of decompression in the East North Central and East South Central census divisions as compared with those in the Pacific and Mid-Atlantic census divisions.

\section{Acknowledgments}

We thank Paul Lin and Phyllis Wright-Slaughter for their expert assistance in use of the data set.

This study was supported by Training Grant No. NS-007222 from the National Institutes of Health (D.A.W.).

\section{References}

1. Aitken LA, Lindan CE, Sidney S, Gupta N, Barkovich AJ, Sorel M, et al: Chiari type I malformation in a pediatric population. Pediatr Neurol 40:449-454, 2009

2. Arnautovic A, Splavski B, Boop FA, Arnautovic KI: Pediatric and adult Chiari malformation Type I surgical series 1965-2013: a review of demographics, operative treatment, and outcomes. J Neurosurg Pediatr 15:161-177, 2015

3. Bollo RJ, Riva-Cambrin J, Brockmeyer MM, Brockmeyer DL: Complex Chiari malformations in children: an analysis of preoperative risk factors for occipitocervical fusion. $\mathbf{J}$ Neurosurg Pediatr 10:134-141, 2012

4. Caldarelli M, Novegno F, Vassimi L, Romani R, Tamburrini G, Di Rocco C: The role of limited posterior fossa craniectomy in the surgical treatment of Chiari malformation Type I: experience with a pediatric series. J Neurosurg 106 (3 Suppl):187-195, 2007

5. Durham SR, Fjeld-Olenec K: Comparison of posterior fossa decompression with and without duraplasty for the surgical treatment of Chiari malformation Type I in pediatric patients: a meta-analysis. J Neurosurg Pediatr 2:42-49, 2008

6. Dyste GN, Menezes AH, VanGilder JC: Symptomatic Chiari malformations. An analysis of presentation, management, and long-term outcome. J Neurosurg 71:159-168, 1989

7. Fenoy AJ, Menezes AH, Fenoy KA: Craniocervical junction fusions in patients with hindbrain herniation and syringohydromyelia. J Neurosurg Spine 9:1-9, 2008

8. Galarza M, Sood S, Ham S: Relevance of surgical strategies for the management of pediatric Chiari type I malformation. Childs Nerv Syst 23:691-696, 2007

9. Gambardella G, Caruso G, Caffo M, Germanò A, La Rosa G, Tomasello F: Transverse microincisions of the outer layer of the dura mater combined with foramen magnum decompression as treatment for syringomyelia with Chiari I malformation. Acta Neurochir (Wien) 140:134-139, 1998
10. Gavrielov-Yusim N, Friger M: Use of administrative medical databases in population-based research. J Epidemiol Community Health 68:283-287, 2014

11. Genitori L, Peretta P, Nurisso C, Macinante L, Mussa F: Chiari type I anomalies in children and adolescents: minimally invasive management in a series of 53 cases. Childs Nerv Syst 16:707-718, 2000

12. Gluncic V, Turner M, Burrowes D, Frim D: Concurrent Chiari decompression and spinal cord untethering in children: feasibility in a small case series. Acta Neurochir (Wien) 153:109-114, 2011

13. Goel A: Is atlantoaxial instability the cause of Chiari malformation? Outcome analysis of 65 patients treated by atlantoaxial fixation. J Neurosurg Spine 22:116-127, 2015

14. Greenberg JK, Ladner TR, Olsen MA, Shannon CN, Liu J, Yarbrough CK, et al: Complications and resource use associated with surgery for Chiari malformation Type 1 in adults: a population perspective. Neurosurgery 77:261-268, 2015

15. Greenberg JK, Ladner TR, Olsen MA, Shannon CN, Liu J, Yarbrough CK, et al: Validation of an International Classification of Diseases, Ninth Revision code algorithm for identifying Chiari malformation Type 1 surgery in adults. Neurosurgery 77:269-273, 2015

16. Greenberg JK, Olsen MA, Yarbrough CK, Ladner TR, Shannon CN, Piccirillo JF, et al: Chiari malformation Type I surgery in pediatric patients. Part 2: complications and the influence of comorbid disease in California, Florida, and New York. J Neurosurg Pediatr 17:525-532, 2016

17. Greenlee J, Garell PC, Stence N, Menezes AH: Comprehensive approach to Chiari malformation in pediatric patients. Neurosurg Focus 6(6):e4, 1999

18. Hwang SW, Heilman CB, Riesenburger RI, Kryzanski J: C1$\mathrm{C} 2$ arthrodesis after transoral odontoidectomy and suboccipital craniectomy for ventral brain stem compression in Chiari I patients. Eur Spine J 17:1211-1217, 2008

19. Iezzoni LI: Assessing quality using administrative data. Ann Intern Med 127:666-674, 1997

20. Kestle JR: Administrative database research. J Neurosurg 122:441-442, 2015

21. Krieger MD, McComb JG, Levy ML: Toward a simpler surgical management of Chiari I malformation in a pediatric population. Pediatr Neurosurg 30:113-121, 1999

22. Ladner TR, Greenberg JK, Guerrero N, Olsen MA, Shannon $\mathrm{CN}$, Yarbrough CK, et al: Chiari malformation Type I surgery in pediatric patients. Part 1: validation of an ICD-9-CM code search algorithm. J Neurosurg Pediatr 17:519-524, 2016

23. Lam S, Harris D, Rocque BG, Ham SA: Pediatric endoscopic third ventriculostomy: a population-based study. J Neurosurg Pediatr 14:455-464, 2014

24. Limonadi FM, Selden NR: Dura-splitting decompression of the craniocervical junction: reduced operative time, hospital stay, and cost with equivalent early outcome. J Neurosurg 101 (2 Suppl):184-188, 2004

25. Massimi L, Peraio S, Peppucci E, Tamburrini G, Di Rocco C: Section of the filum terminale: is it worthwhile in Chiari type I malformation? Neurol Sci 32 (Suppl 3):S349-S351, 2011

26. McGirt MJ, Attenello FJ, Datoo G, Gathinji M, Atiba A, Weingart JD, et al: Intraoperative ultrasonography as a guide to patient selection for duraplasty after suboccipital decompression in children with Chiari malformation Type I. J Neurosurg Pediatr 2:52-57, 2008

27. Meadows J, Kraut M, Guarnieri M, Haroun RI, Carson BS: Asymptomatic Chiari Type I malformations identified on magnetic resonance imaging. J Neurosurg 92:920-926, 2000

28. Milhorat TH, Bolognese PA, Nishikawa M, Francomano CA, McDonnell NB, Roonprapunt C, et al: Association of Chiari malformation type I and tethered cord syndrome: pre- 
liminary results of sectioning filum terminale. Surg Neurol 72:20-35, 2009

29. Milhorat TH, Chou MW, Trinidad EM, Kula RW, Mandell $\mathrm{M}$, Wolpert C, et al: Chiari I malformation redefined: clinical and radiographic findings for 364 symptomatic patients. Neurosurgery 44:1005-1017, 1999

30. Morris Z, Whiteley WN, Longstreth WT Jr, Weber F, Lee YC, Tsushima Y, et al: Incidental findings on brain magnetic resonance imaging: systematic review and meta-analysis. BMJ 339:b3016, 2009

31. Motheral B, Brooks J, Clark MA, Crown WH, Davey P, Hutchins D, et al: A checklist for retrospective database studies-report of the ISPOR Task Force on Retrospective Databases. Value Health 6:90-97, 2003

32. Navarro R, Olavarria G, Seshadri R, Gonzales-Portillo G, McLone DG, Tomita T: Surgical results of posterior fossa decompression for patients with Chiari I malformation. Childs Nerv Syst 20:349-356, 2004

33. Newman-Casey PA, Talwar N, Nan B, Musch DC, Pasquale LR, Stein JD: The potential association between postmenopausal hormone use and primary open-angle glaucoma. JAMA Ophthalmol 132:298-303, 2014

34. Ney JP, Johnson B, Knabel T, Craft K, Kaufman J: Neurologist ambulatory care, health care utilization, and costs in a large commercial dataset. Neurology 86:367-374, 2016

35. Park TS, Hoffman HJ, Hendrick EB, Humphreys RP: Experience with surgical decompression of the Arnold-Chiari malformation in young infants with myelomeningocele. Neurosurgery 13:147-152, 1983

36. Royo-Salvador MB, Solé-Llenas J, Doménech JM, GonzálezAdrio R: Results of the section of the filum terminale in 20 patients with syringomyelia, scoliosis and Chiari malformation. Acta Neurochir (Wien) 147:515-523, 2005

37. Sarrazin MS, Rosenthal GE: Finding pure and simple truths with administrative data. JAMA 307:1433-1435, 2012

38. Shweikeh F, Sunjaya D, Nuno M, Drazin D, Adamo MA: National trends, complications, and hospital charges in pediatric patients with Chiari malformation type I treated with posterior fossa decompression with and without duraplasty. Pediatr Neurosurg 50:31-37, 2015

39. Smith BW, Strahle J, Bapuraj JR, Muraszko KM, Garton HJ, Maher CO: Distribution of cerebellar tonsil position: implications for understanding Chiari malformation. J Neurosurg 119:812-819, 2013

40. Smith-Bindman R, Miglioretti DL, Johnson E, Lee C, Feigelson HS, Flynn M, et al: Use of diagnostic imaging stud- ies and associated radiation exposure for patients enrolled in large integrated health care systems, 1996-2010. JAMA 307:2400-2409, 2012

41. Strahle J, Muraszko KM, Kapurch J, Bapuraj JR, Garton HJ, Maher CO: Chiari malformation Type I and syrinx in children undergoing magnetic resonance imaging. J Neurosurg Pediatr 8:205-213, 2011

42. Tubbs RS, Beckman J, Naftel RP, Chern JJ, Wellons JC III, Rozzelle CJ, et al: Institutional experience with 500 cases of surgically treated pediatric Chiari malformation Type I. J Neurosurg Pediatr 7:248-256, 2011

43. Tubbs RS, McGirt MJ, Oakes WJ: Surgical experience in 130 pediatric patients with Chiari I malformations. J Neurosurg 99:291-296, 2003

44. Vernooij MW, Ikram MA, Tanghe HL, Vincent AJ, Hofman A, Krestin GP, et al: Incidental findings on brain MRI in the general population. N Engl J Med 357:1821-1828, 2007

45. Yao X, Abraham NS, Alexander GC, Crown W, Montori VM, Sangaralingham LR, et al: Effect of adherence to oral anticoagulants on risk of stroke and major bleeding among patients with atrial fibrillation. J Am Heart Assoc 5:003074, 2016

46. Yeh DD, Koch B, Crone KR: Intraoperative ultrasonography used to determine the extent of surgery necessary during posterior fossa decompression in children with Chiari malformation type I. J Neurosurg 105 (1 Suppl):26-32, 2006

\section{Disclosures}

The authors report no conflict of interest concerning the materials or methods used in this study or the findings specified in this paper.

\section{Author Contributions}

Conception and design: Maher, Wilkinson. Acquisition of data: all authors. Analysis and interpretation of data: Maher, Wilkinson, Johnson. Drafting the article: Maher, Wilkinson. Critically revising the article: all authors. Reviewed submitted version of manuscript: all authors. Approved the final version of the manuscript on behalf of all authors: Maher. Study supervision: Maher.

\section{Correspondence}

Cormac O. Maher, Department of Neurosurgery, University of Michigan, 1500 E Medical Center Dr., Rm. 3552 Taubman Center, Ann Arbor, MI 48109-5338. email: cmaher@med.umich.edu. 